\title{
Karpal Tünel Sendromu Tanılı Erkek Olguların Klinik ve Elektrofizyolojik Bulgularının Meslek Hastalığı, Obezite ve Sigara Kullanımıyla İlişkisinin Değerlendirilmesi
}

\section{Clinical and Neurophysiological Evaluation of the Male Patients with Carpal Tunnel Syndrome with Regard to Relationship among Occupational Disease, Obesity and Smoking}

\author{
${ }^{1}$ Sibel ÜSTÜN ÖZEK, ${ }^{1}$ Canan EMIR, ${ }^{2}$ Rahşan Adviye ŞAHIN İNAN
}

${ }^{1}$ Sağlık Bilimleri Üniversitesi, Prof.Dr.Cemil Taşçığlu Şehir Hastanesi, Nöroloji Kliniği, İstanbul, TÜRKIYE

${ }^{2}$ Sağglık Bilimleri Üniversitesi, Kartal Dr.Lütfi Kırdar Eğitim ve Araştırma Hastanesi, Nöroloji Kliniği, İstanbul, TÜRKIYY

\author{
Sibel Üstün Özek: https://orchid.org/0000- 0003- 1165-2648 \\ Canan Emir: https://orcid.org/ 0000-0002-5418-930X \\ Rahşan Adviye Şahin İnan :https://orcid.org/0000-0002-6084-055X
}

\begin{abstract}
ÖZ
Amaç: Bu çalışmada elektrofizyolojik olarak karpal tünel sendromu (KTS) tanısı almış erkek olgularda sigara kullanımı, obezite, yaş, meslek ve meslek süreleri ile KTS ilișkisinin araştırılmasını amaçladık.

Materyal ve Metot: Çalışmaya KTS tanısı konulan 50 erkek olgu dahil edildi. Hastaların yaşı, semptom süreleri, el dominansları, meslekleri ve meslek süreleri, sigara kullanımları ve vücut kitle indeksi (VKI) kaydedildi. Semptom şiddeti Boston semptom şiddet skalası (BSŞS) ve fonksiyonel kapasite skorları (FKS) ile değerlendirildi. Elektrofizyolojik değerlendirmede bilateral ulnar median duysal ve motor sinir ileti incelemeleri çalışıldı.

Bulgular: Hastaların yaş ortalaması $48,40 \pm 9,61$ yıldı. Mesleki dağılımları büyük oranda inşaat, tekstil, ayakkabı işçileri ve aşçılardan oluşturmaktaydı. BSŞS ortalaması $22,88 \pm 8,385$ ve FKS $11,40 \pm 4,527$ idi. VKİ $<25$ ile $>25$ üzeri olan KTS'lı hastaların yaş, semptom süresi, semptom şiddet ve FKS arasında istatistiksel olarak anlaml fark saptanmadi. Meslek süreleri ve sigara kullanımıyla hastalık şiddeti arasında bir ilişki saptanmadı.

Sonuç: Erkek KTS özellikle tekstil, inşaat işçileri,ayakkabı üreticileri ve aşçılar gibi işçi sınıfında yüksek oranda görülür. Obezite dereceleri ve sigara kullanımıyla hastalık şiddeti arasında anlamlı ilişki saptamamakla birlikte daha büyük vaka serileri üzerinde çalışmak gereklidir. Çalışanların KTS ile ilgili bilinçlenmesi ve meslek hastalı̆̆ farkındalığının oluşturulması önemlidir.

Anahtar Kelimeler: Erkek, karpal tünel sendromu, meslek hastalıkları, obezite, sigara
\end{abstract}

\section{ABSTRACT}

Objective: In this study, we aimed to investigate the relationship with the smoking, obesity, age, occupation and duration of occupation and carpal tunnel syndrome (CTS) in male patients with electrophysiologically diagnosed as having CTS.

Materials and Methods: 50 male patients with CTS were included into the study. Age, duration of the symptoms, dominant hand, occupation, duration of occupation, smoking status and body mass index (BMI) for all the patients were recorded. Boston Symptom Severity Scale (BSSS) and functional capacity score (FCS) was used for the assessment of the symptom severity. For the electrophysiological evaluation, sensory and motor conduction studies of bilateral median and ulnar nerves were performed.

Results: Mean age of the patients was $48.40 \pm 9.61$ years. Distribution of the occupations were mostly included the workers of construction, textile, shoemaker and the cooks. The mean score of BSSS and FCS were $22.88 \pm 8.385$ and $11.40 \pm 4.527$, respectively. No statistically significant difference was found between the subjects with BMI $<25$ and BMI $>25$. CTS patients regarding the age, symptom duration, BSSS and FCS. Duration of the occupation and smoking status did not show any significant correlation with the disease severity.

Conclusion: CTS in males is specifically mostly seen in the workers of construction, textile, shoemaker and the cooks. Although we found no significant association between disease severity and obesity or smoking, studies on larger case series are necessary. To raise awareness of the patients about CTS and occupational disease is an important issue.

Keywords: Carpal tunnel syndrome, male, obesity, occupational diseases, smoking
Sorumlu Yazar / Corresponding Author:

Sibel Üstün Özek

Sağlık Bilimleri Üniversitesi,Prof.Dr.Cemil Taşçıŏlu Şehir

Hastanesi, Nöroloji Kliniği, İstanbul

Tel: +905325969090

E-mail: sibelustun@hotmail.com
Yayın Bilgisi / Article Info:

Gönderi Tarihi/ Received: 03/09/2020

Kabul Tarihi/ Accepted: 08/10/2020

Online Yayın Tarihi/ Published: 30/12/2020

Atıf / Cited: Üstün Özek S ve ark. Karpal Tünel Sendromu Tanılı Erkek Olguların Klinik ve Elektrofizyolojik Bulgularının Meslek Hastalığı, Obezite ve Sigara Kullanımıyla İlişkisinin Değerlendirilmesi. Online Türk Sağllk Bilimleri Dergisi 2020;5(4):612-621. doi: 10.26453/ otjhs. 790210 


\section{GíRIŞ}

Karpal tünel sendromu (KTS) median sinirin el bileğinde tuzaklanması ile ortaya çıkar ve üst ekstremitenin en sık görülen nöropatisidir. Klinik olarak median sinir innervasyonunda ağrı ve uyuşukluk, el sallama ile yakınmaların azalması, tekrarlayan el bilek hareketleriyle yakınmalarının artması, Tinel ve Phalen işaretlerinde pozitiflik, tenar bölgede atrofi sayılabilir. Karpal tünel erkeklerde kadınlara göre daha az görülmektedir. ${ }^{1,2}$ Sistemik hastalıklardan diyabetes mellitus, hipotiroidi, romatoit artrit, osteoartrit basınç artışı ile ilişkili olmakla birlikte çoğu basınç artışının nedeni idiyopatiktir. Tekrarlayan el bileği hareketleri, güçlü ve zorlayıcı el hareketleri, titreşimli el aletlerinin kullanımı riski arttırır. Uzun süreli ve düzenli el titreşim aletlerinin kullanılması ve uzun süreli ve tekrarlayan fleksiyon ve ekstansiyon hareketleri karpal tünel sendromu riskini artt1rır. ${ }^{3}$ Ağır mesleki kullanımla karpal tünel tenosinovyal kalınlaşma izlenir. ${ }^{4}$ Sürekli yüksek intrakarpal basınç median sinir kanlanmasını bozar ve median sinir iskemisine, lokal demiyelinizasyona ve sonunda aksonal hasara yol açar. ${ }^{5}$ Hatta basınç kanaldaki subsnovyal konnektif dokuda kalınlaşma ve fibrosise yol açar. Mesleki faktörler, obezite ve sigara ayrı ayrı KTS üzerine etkisi olabilecek risk faktörleridir. ${ }^{3,6,7}$ Bazen bu risk faktörleri birbiri içine geçebilir. Örneğin stresli ve iş yükü fazla olan bir meslekte çalışanın sigara içmesini arttırması buna örnek verilebilir. ${ }^{7}$ Ancak tüm bu faktörler nörotoksisite, basınç ve iskeminin artması üzerinden ortak patogenetik yolları tetikleyebilir. Bizim bu çalışmadaki amacımız laborotuvarımıza başvuran ve karpal tünel sendromu tanısı alan erkek hastaların sigara kullanımı, obezite, yaş, meslek ve meslek süreleri ile ilişkisini ortaya koymak ve şiddet skalası ve EMG bulguları ile korelasyonun araştırılmasıdır.

\section{MATERYAL VE METOT}

Çalışma için Sağlık Bilimleri Üniversitesi Okmeydanı Eğitim ve Araştırma Hastanesi Klinik Araştırmaları Etik Kurulu'ndan izin alınmıştır (Tarih: 19.06.2018, karar no: 938).

Çalışmaya kliniğimiz nörofizyoloji bölümü EMG laboratuarına başvuran ve KTS tanısı konulan 50 erkek olgu dahil edildi. Diyabetes mellitus, tiroid böbrek ve konnektif doku hastalığı, malignite ve servikal diski olanlar çalışmaya dahil edilmedi. Yaş, semptom süresi, el dominans1, meslekleri ve meslek süreleri, sigara kullanımı ve vücut kitle indeksi

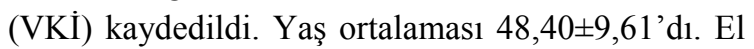

dominans1 \%92 sağ, \%8'inde soldu. Hastaların semptomları için Boston şiddet skalası kullanıldı. Boston anketi Levie ve ark. tarafindan 1993 de geliştirilmiş ve Sezgin ve ark. tarafından Türkçe geçerlilik ve güvenirliliği oluşturulmuştur. ${ }^{8}$ Bu skala 2 ayrı bölümden oluşmaktadır:

1. Boston semptom şiddet skalası (BSŞS) ağır parestezi ve güçsüzlüğü belirleyen 11 maddesi vardır. Toplam puan minimum 11 maksimum 55 puandır.

2. Fonksiyonel kapasite skoru (FKS) el ile ilgili maddeleri içeren 8 maddeden oluşmaktadır. Toplam puan minimum 8 maksimum 40 puandır.

Sinir iletim çalışmalarında median motor sinir distal latansı (DL), median motor sinir iletim hızı (MİH), bilek seviyesinde median motor sinir birleşik kas aksiyon potansiyeli amplitüdü (BKAP), median motor sinir dirsek seviyesinde BKAP, 2. parmak-bilek segmenti median sinir duyusal iletim hızı (DİH), avuç içi-bilek segmenti DİH, 2. parmak-bilek segmenti median sinir duyusal sinir aksiyon potansiyeli (DAP) amplitüdü, avuç içi-bilek segmenti DAP ölçüldü. Median motor DL $4 \mathrm{~ms}$ üzeri, amplitüd $5 \mathrm{mV}$ nın altı ve ileti hızı $50 \mathrm{~m} / \mathrm{sn}$ altında olanlar patolojik olarak kabul edildi. Median duysal ileti incelemeleri için DL 3,2'den uzun, amplitüdü $12 \mathrm{mV}$ altında ve ileti hızı $45 \mathrm{~m} / \mathrm{s}$ altında olanlar patolojik kabul edildi. Parmak bilek iletim hızları normal olanlarda IV. parmak uyarımlı median duysal tepe latansı ulnarise kıyasla 0,5 msn uzun olanlar patolojik kabul edildi. Hastalar dominant ekstremite elektrofizyolojik bulgularına göre hafif, orta ve ağır KTS olmak üzere 3 gruba ayrildı. Sadece duysal etkilenme olanlar hafif, duysal etkilenme ile birlikte hafif-orta düzeyde distal motor latans gecikmesi olanlar orta, duysal yanıtın alınamadığı ve ileri distal motor latans gecikmesi olanlar ağır olarak sınıflandırıldı (Tablo 1).

Istatistiksel Analiz: Araştırma verilerinin istatistiksel analizi, bilgisayar ortaminda SPSS 20.0 paket programında sayı, yüzde, ortalama, standart sapma hesaplanarak, Ki kare, Mann-Whitney U testi, korelasyon analizi kullanılarak yapıldı. Çalışmada, anlamlılık düzeyi p<0,05 anlamlı kabul edildi.

\section{BULGULAR}

Çalışmamıza yaş aralığı 19-66, ortalama yaş

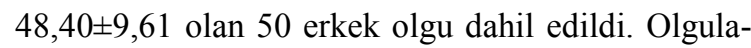
rın \%92'si (46 olgu) sağ, \%8'i (4 olgu) sol el dominanttı. Bizim hastalarımızın en büyük oranını inşaat, tekstil, ayakkabı işçileri ve aşçılar oluşturmaktaydı. Bu grup içinde büyük bir kısmı inşaat işçileri, ikinci büyük grup ise ayakkabı, tekstil ve çanta imalatçıla- 
rıydı. Olguların çoğu işçi sınıfında ve ağır işlerde çalışmaktaydı. Beyaz yakalı ve masa başı çalışan 2 olgumuz vardı (Tablo 2).

Karpal tünel bulguları \%12 oranında dominant, \%20 nondominant, \%68 oranında bilateral olarak izlendi. Olguların \%18 (9 olgu) ine ulnar tuzak nöropati eşlik etmekteydi. Ulnar tuzak nöropatilerin 6's1 sol, 2'si sağ, 1'i bilateraldi. Tüm olgular sağ el dominanttı ve ulnar tuzak nöropatideki nondominant ekstremite baskınlığı dikkat çekiciydi. \%36'sı (18 olgu) normal kilolu iken, \%32'si (16 olgu) fazla kilolu, \% 28 'i (14 olgu) obez ve \% 4 ü (2 olgu) si morbid obez olarak değerlendirildi.

Semptom şiddet skorları ortalama $22,88 \pm 8,385$ ve

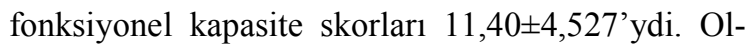
gularımızın büyük bir kısmında BSŞS hafif ya da orta değerdeydi (Sekil 1-2). FKS puan toplamı daha düşük değerde saptandı. Hastalık şiddeti ile BSŞS ve FKS arasında fark saptanmadı. Tüm olguların \%34' ü (17 olgu) sigara içmezken, \%16'sı (8 olgu) eski içici (bırakalı en az 2 yıl olmuş) ve \%50'si (25 olgu) halen sigara içenlerden oluşmaktaydı. Obez ve obez olmayan KTS'li hastaların yaşları, semptom süreleri, semptom şiddet ve fonksiyonel kapasite skorları arasında istatistiksel olarak anlamlı fark saptanmadı. Hastalık Şiddeti ile BSŞS arasında $(r=0,186$, $\mathrm{p}=0,196)$ ve Boston FKS değerleri arasında $(\mathrm{r}=0,209, \mathrm{p}=0,146)$ ilişki olmadığı görüldü.

Hastalık şiddet değeri bilateral KTS bulguları olanlarla nondominantlar karşılaştırıldığında anlamlı yüksek saptand1 $(p<0,05)$. Dominant ve bilateral tutulumu olanlarla dominant ve nondominantlar arasında hastalık şiddeti açısından anlamlı fark yoktu $(\mathrm{p}>0,05)$ (Tablo 3). Meslek süreleri $(\mathrm{p}=0749)$, obezite dereceleri $(p=0755)$ ve sigara içme $(p=0755) d u-$ rumlarına göre hastalık şiddetlerinde bir farklılık olmadığı görüldü. Meslek süreleri $(p=0,850)$, obezite dereceleri $(p=0,122)$ ve sigara içme $(p=0,322) d u-$ rumlarına göre ulnar tuzak birliktelikleri bakımından bir farklılık olmadığı görüldü, obezite olanlarla olmayanlar arasında fonksiyonel kapasite açısından anlamlı fark saptanmadi.

\section{TARTIŞMA VE SONUÇ}

Üst ekstremitedeki basınç yaklaşık $8 \mathrm{mmHg}$ iken KTS ile bu basınç $30 \mathrm{mmHg}$ ya çıkmakta hatta el bileğinin tekrarlayan hareketleri ile $90 \mathrm{mmHg}$ ya kadar çıkmaktadır., ${ }^{9,10} \mathrm{Bu}$ basınç artışı çoğu olguda idiyopatik olabilir. Bazı olgulara diyabet, hipotiroidi, romatoid artrit ve osteoartrit eşlik edebilir. Obezitenin özellikle VKİ 25 in üzerinde ise basınç artması konusunda riski arttırdığı bildirilmiştir. ${ }^{11}$ Obezite günümüzde global bir sağlık sorunudur. Vücut kitle indeksinin KTS ye etkisi kadın ve erkeklerde farkl1lık göstermemektedir. Vücut kitle indeksinin artış1nın hangi mekanizmalarla KTS ye neden olduğu bilinmemektedir. Tüneldeki yağ dokusu intrakarpal basıncı arttırır ve yavaş yavaş tünelde sıkışmaya neden olur. Sinirde iskemi ve fokal demyelinizasyon meydana gelir. Obezite genellikle metabolik sendromun bir bileşenidir ve sıklıkla periferik nöropati ile birliktedir. Kilo artışı diyabet riskini arttırmaktadır. Ancak bizim değerlendirdiğimiz hastaların bilinen diyabet ya da glukoz tolerans bozukluğu mevcut değildi. Vücut kitle indeksinin artışı belirgin derecede KTS riskini arttırmaktadır. Mesleki riskler ve tekrarlayan el hareketleri ile risk daha da artmaktadır. ${ }^{6}$ Hastaların \%36'sı normal kilolu iken, \%32'si fazla kilolu, \%28'i obez ve \% 4'ü morbid obez olarak değerlendirildi. Ancak biz hastalarımızda obezite şiddeti ile KTS bulgularını arasında anlamlı bir fark saptamadik ( $\mathrm{p}=0,755)$. Hasta grubumuzdaki morbid obez olan hasta sayımızın oranı diğer gruplara göre daha azdı. Daha çok morbid obez içeren bir grup ile çalışmanın değerlendirilmesi düşünülebilir.

KTS kısa ve geniş ellilerde uzun elli olanlara göre daha yaygındır. Kare şeklindeki bilekte median sinir travmalara daha açıktır. ${ }^{11}$ Uzun süreli ve düzenli el titreşim aletlerinin kullanılması ve uzun süreli tekrarlayan fleksiyon ve ekstansiyon hareketleri KTS riskini arttırır. ${ }^{3}$ İntrakarpal basınç artışı ile oluşan doku iskemisi, mesleki iş yükü faaliyetlerinden olumsuz etkilenir. KTS genel prevalansı kadınlarda $\% 3,4$ iken erkeklerde \%0,06 dır. ${ }^{1,2}$ Prevelansı çalışılan enstitüye göre \%3-11 arasında değişmektedir. ${ }^{3,10}$ Çalışanlarda görülen prevalans normal popülasyona göre yüksek orandadır. Önemli disabilite üretimde azalma ve iş kaybına yol açar. Bizim hastalarımızın en büyük oranını inşaat, tekstil, ayakkabı işçileri ve aşçılar oluşturmaktaydı (Tablo 2). Tekrarlayan el hareketlerinin sıklığı ve yapılan işin ağırlığı semptomları ortaya çıkarmaktadır.

Özellikle erkeklerde klinik bulgular daha hafif olarak bildirilmiş ancak ağır elektrofizyolojik hasar saptanmıştır. Özellikle riskli meslek gruplarında hastaların yakın takibi ve elektrofizyolojik incelemeler iş sağlığı açısından göz önünde bulundurulmalıdır. Gecikmiş tanı ve ilerlemiş karpal tünel bulguları olguların uzun süre iş gücü kaybına yol açıp toplum ve aile için ekonomik kayba yol açmaktadır. Kadın ve erkek ressamların uzun dönemli takipleri ile yapılmış bir çalışmada benzer iş yüküne sahip olmalarına rağmen kadınlarda riski daha yüksek saptamışlardır. ${ }^{12}$ Yapılan çalışmaların bazılarında tekrarlayan 
el hareketleri ile ilişki saptanırken bazılarında bu ilişki ortaya konmamıştır. ${ }^{13,14}$ Tekrarlayan el hareketlerinden ziyade zor ve güç gerektiren işlerde çal1şanlarda prevelans daha fazla verilmiştir. ${ }^{15}$ Bizim çalışma grubumuzdaki hastaların büyük bir kısmını inşaat işçileri oluşturmaktaydı. Bu grup hasta bir takım inşaat aletlerini kullanmakta ve güç gerektiren işlerde çalışmaktaydılar. İkinci büyük grubu oluşturan ayakkabı, tekstil ve çanta imalatçılarıydı. Bu grup işçiler de sürekli bir alet ile çalışmaktaydılar. Hastalarımızın \%18'ine ulnar tuzak bulguları da mevcuttu. Bu da mesleki risklerin, oturuş postürü ve kullanılan aletlere bağlı olarak multipl tuzaklanmalar1 kolaylaştırdığı yönünde değerlendirilebilir.

Hem kadın hem de erkek popülasyonda 6 mesleği yüksek risk grubunda sınıflamışlardır. Bu meslekler montajcilar, inşaat işçileri, paketleme ve makine operatörleri, kapıcılar ve temizlik işçileri ve veri giriş elemanları olarak sınıflandırılmıştır. ${ }^{16}$ Bizim hastalarımızın mesleki dağılımı bu bulguları desteklemektedir. Ancak meslek dağılımları istatistik veriler açısından karşılaştırma yapacak homojenlikte değildir.

Mesleki yönden iş memnuniyetsizliği olan olgularda ağrı uyuşukluk gibi semptomlara duyarlılığın fazla olduğu ve şikayetlerinin daha hafif düzeyde tuzak bulguları varken belirgin olduğu söylenmiştir. Semptomlar üzerinde psikososyal faktörlerin de etkisi olduğu açıktır. Ancak hastalarımızda depresyon anketi ya da işyeri memnuniyeti ile ilgili bir anket uygulamadık. ${ }^{17}$ Yapılacak çalışmaların memnuniyet anketleri ile desteklenmesi anlamlı olabilir.

Erkek olgularda hastalık şiddeti ağır iken hastanın yakınmaları daha azdır. ${ }^{5}$ Hastalarımızın tek geçim kaynakları meslekleri ve çoğu çocukluktan beri bu işlere devam etmekteydi. Hastaların hiçbiri bunun bir meslek hastalığı olabileceğinin farkında değildi. Çoğunluğun yaptığı iş kendine ait uzun süredir yapmakta oldukları mesleklerdi. İşçi sağlığı ve güvenliği sistemi üzerinden tarafimıza başvuru olmadı. Hastaların bu konuda bilgilendirilmeleri, çalıştıkları departmanın değiştirilmesi ya da başka bir bölümde istihdam edilmelerinin hastalı progresyonuna etkisi vardir.

Sigara ile ilişkisini ortaya koymak için yapılan çalışmalarda pozitif ilişki saptandığı gibi,ilişki olmadığını bildiren çalışmalar da olmuştur. ${ }^{18,19}$ Kesitsel çalışmalarda sigara içme ile KTS ilişkisi ortaya konmuşken vaka kontrollü ve kohort çalışmalarında bu gösterilememiştir. Kesitsel çalışmalardaki ilişki eşlik eden başka bulgularla da ilişkili olabilir. Stresli ve iş yükü fazla iş gruplarında çalışanlarında sigara içimi daha fazla olacağından bu da riski arttırır. Sigara içmek vaskuler yapıyı bozup median sinirin duyarlılığını arttırır. Üzerine eklenen fiziksel yük ve stres doku iskemisini tetikler ve dejenerasyon ve fibrosis oluşur. Ayrıca sigaranın toksik nöropati etkisi de vardır. ${ }^{7}$ Ulnar tuzak ve sigaranın ilişkisinin araştırıldığı bir çalışmada sigara içerken tekrarlayan dirsek hareketlerinin kümülatif etkisi ile tetiklenen nöropatik faktörler rol oynar. ${ }^{20}$ Bizim çalışmamızdaysa KTS'li olgularda eski sigara içenler ve halen sigara içenlerle içmeyenler karşılaştırıldığında anlamı fark saptanmadi $(\mathrm{p}=0,755)$.

Sonuç olarak, erkek olgularda KTS özellikle tekstil , inşaat işçileri ve aşçılarda yüksek oranda saptandı. Obezite şiddeti ve sigara kullanımı ile KTS arasında anlamlı ilişki bulunmadı. Hastaların KTS ile ilgili bilinçlenmesi ve meslek hastalığı farkındalığının oluşturulması önemlidir. Ancak çalışma şartlarının değiştirilmesi ve iyileştirilmesi hastalık regresyonuna neden olmakla birlikte sosyoekonomik nedenlerle bunun her zaman çok kolay olmadığı görülmektedir.

Etik Komite Onayr: Çalışma için Sağlık Bilimleri Üniversitesi Okmeydanı Eğitim ve Araştırma Hastanesi Etik Kurulu'ndan etik onayı alındı (Tarih: 19.06.2018, karar no: 938).

Çıkar Çatışması: Yazarlar çıkar çatışması bildirmemişlerdir.

Yazar Katkılart: Fikir - SÜÖ; Denetleme - CE; Malzemeler - SÜÖ, CE; Veri toplanması ve/veya işlemesi - SÜÖ, CE; Analiz ve/veya yorum - SÜÖ, RAŞI; Yazıyı yazan - SÜÖ, RAŞI.

Hakem değerlendirmesi: Dış bağımsız.

\section{KAYNAKLAR}

1. Burke DT, Burke MM, Stewart GW, Cambre A. Splinting for carpal tunnel syndrome: insearch of the optimal angle. Arch Phys Med Rehabil. 1994;75:1241-1244.

2. Provinciali L, Giattini A, Splendiani G, Logullo F. Usefulness of hand rehabilitation after carpal tunnel surgery. Muscle Nerve. 2000;23:211-216.

3. Palmer KT, Harris EC, Coggon D. Carpal tunnel syndrome and its relation to occupation: A systematic literature review. Occup Med. 2007;7 (1):57-66.

4. Pickering SA, Stevens A, Davis TR. Work practices and histopathological changes in the tenosynovium in carpal tunnel syndrome in men. Journal of Hand Surgery. 2004;29(4):325-328. 
5. Watts AC, McEachan J. Carpal tunnel syndrome in men. Current Orthopaedics. 2006;20(4):294298.

6. Shiri R, Pourmemari MH, Falah-Hassani K, Viikari-Juntura E. The effect of excess body mass on the risk of carpal tunnel syndrome: a meta-analysis of 58 studies. World Obesity. 2015;16(12):1094-1104.

7. Pourmemari MH, Juntura EV, Shiri R. Smoking and carpal tunnel syndrome: A meta-analysis. Muscle Nerve. 2014;49(3):345-350.

8. Sezgin M, Incel NA, Serhan S et al. Assessment of symptom severity and functional status in patients with carpal tunnel syndrome: reliability and functionality of the Turkish version of the Boston Questionnaire. Disabil Rehabil. 2006;28 (20):1281-1285.

9. Okutsu I, Ninomiya S, Hamanaka I, Kuroshima $\mathrm{N}$, Inanami $\mathrm{H}$. Measurement of pressure in the carpal canal before and after endoscopic management of carpal tunnel syndrome. The Journal of Bone and Joint. Surgery. 1989;71(5):679-683.

10. Silverstein BA, Fan ZJ, Bonauto DK, et al. The natural course of carpal tunnel syndrome in a working population. Scand J Work Environ Health. 2010;36(5):384-393.

11. Shiri R. A. square-shaped wrist as a predictor of carpal tunnel syndrome: A meta-analysis. Muscle Nerve. 2015;52(5):709-713.

12. Heilskov-Hansen T, Mikkelsen S, Svendsen SW, et al. Exposure-response relationships between movements and postures of the wrist and carpal tunnel syndrome among Male and female house painters: a retrospective cohort study. Occupational Environmental Medicine. 2016;73(6):401408.

13. Bonfiglioli R, Mattioli S, Armostrong T, et al. Validation of the ACGIH TLV for hand activity in the OCTOPUS cohort: A two-year longitudinal study of carpal tunnel syndrome. Scand J Work Environ Health. 2013;39(2):155-163.

14. Nathan PA, Istvan JA, Meadows KD. A longitudinal study of predictors of research-defined carpal tunnel syndrome in industrial workers: Findings at 17 years. Journal of Hand Surgery. 2005;30:593-598.

15. Fan ZJ, Harris-Adamson C, Gerr F et al. Associations Between Workplace Factors and Carpal Tunnel Syndrome: A Multi-Site Cross Sectional Study .American Journal of Industrial Medicine. 2015;58:509-518.
16. McDiarmid M, Oliver M, Ruser J, Gucer P. Male and Female Rate Differences in Carpal Tunnel Syndrome Injuries: Personal Attributes or Job Tasks? Environmental Research Section. 2000;83(1):23-32.

17.Jason TG, Scott DM, Anthony JW, Alan LC. Occupational and Biopsychosocial Risk Factors for Carpal Tunnel Syndrome. Journal of Occupational and Environmental Medicine. 2014;56 (9):965-972.

18. Pourmemari MH, Heliövaara M, Viikari-Juntura E, Shiri R. Carpal tunnel release: Lifetime prevalence, annual incidence, and risk factors. Muscle\&Nerve. 2018;58(4):497-502.

19. Nathan PA, Keniston RC, Lockwood RS, Meadows KD. Tobacco, Caffeine, Alcohol, and Carpal Tunnel Syndrome in American Industry: A Cross -Sectional Study of 1464 Workers. Journal of Occupational \& Environmental Medicine. 1996;38(3):290-298.

20. Richardson JK, Jamieson SC. Cigarette smoking and ulnar mononeuropathy at the elbow. American Journal of Physical Medicine\& Rehabilitation. 2004;83(9):730-734. 
Tablo 1. Hastalık şiddet dağılımı.

\begin{tabular}{|l|c|c|}
\hline Hastalık şiddeti & Sıklık & Yüzde \\
\hline Çok hafif & 3 & 6,0 \\
\hline Hafif & 12 & 24,0 \\
\hline Orta & 19 & 38,0 \\
\hline Ağır & 4 & 8,0 \\
\hline Sağ hafif-sol orta & 8 & 16,0 \\
\hline Sağ orta-sol hafif & 4 & 8,0 \\
\hline Total & 50 & 100 \\
\hline
\end{tabular}


Tablo 2. Meslek dağılımı ve sür eler i.

\begin{tabular}{|l|c|c|c|}
\hline Meslek & Sıklık & Yüzde & Meslek Süresi (Yıl) \\
\hline Aşçı & 5 & 10 & $10-38$ \\
\hline Ayakkabı işçisi & 3 & 6,0 & $28-33$ \\
\hline Bakkal & 1 & 2,0 & 28 \\
\hline Boya işçisi & 2 & 4,0 & $9-20$ \\
\hline Büfeci & 1 & 2,0 & 26 \\
\hline Cam işçisi & 2 & 4,0 & $20-35$ \\
\hline Çanta imalatçısı & 1 & 2,0 & 5 \\
\hline Çiftçi & 1 & 2,0 & 38 \\
\hline Ekmek fabrikası işçisi & 1 & 2,0 & 3 \\
\hline Elektrikçi & 1 & 2,0 & 26 \\
\hline İnşaat işçisi & 7 & 14,0 & $8-35$ \\
\hline Temizlik işçisi & 3 & 6,0 & $17-25$ \\
\hline Kablo işçisi & 1 & 2,0 & 42 \\
\hline Kasap & 3 & 6,0 & $10-30$ \\
\hline Marangoz & 1 & 2,0 & 28 \\
\hline Markette yuk taşıor & 1 & 2,0 & 23 \\
\hline Masa baş1 çalışan1 & 2 & 4,0 & $26-27$ \\
\hline Matbaacılık & 2 & 4,0 & $27-30$ \\
\hline Mobilya cilacısı & 1 & 2,0 & 43 \\
\hline Motor tamircisi & 1 & 2,0 & 21 \\
\hline Nalbur & 1 & 2,0 & 30 \\
\hline Pizza ustası & 1 & 2,0 & 15 \\
\hline Şoför & 1 & 2,0 & 48 \\
\hline Tamirci & 2 & 4,0 & $18-34$ \\
\hline Tekstil işçisi & 3 & 6,0 & $15-25$ \\
\hline Ütücü & 1 & 2,0 & 22 \\
\hline Yol yapım işçisi & 1 & 2,0 & 3,5 \\
\hline & & & \\
\hline
\end{tabular}


Tablo 3. Hastalık şiddetinin dominant ve nondominant ekstremiteye göre dağılımı.

\begin{tabular}{|c|c|c|c|c|c|c|}
\hline \multicolumn{2}{|c|}{ Taraf } & $\mathbf{N}$ & Mean Rank & Sum of & Mann- & $\mathbf{p}$ \\
\hline \multirow{3}{*}{$\begin{array}{c}\text { Hastalık } \\
\text { şiddeti }\end{array}$} & Dominant & 6 & 8,75 & 52,50 & \multirow[t]{3}{*}{28,500} & \multirow[t]{3}{*}{0,860} \\
\hline & Nondominant & 10 & 8,35 & 83,50 & & \\
\hline & Total & 16 & & & & \\
\hline \multirow{3}{*}{$\begin{array}{c}\text { Hastalık } \\
\text { şiddeti }\end{array}$} & Dominant & 6 & 13,33 & 80,00 & \multirow[t]{3}{*}{59,000} & \multirow[t]{3}{*}{0,091} \\
\hline & Bilateral & 34 & 21,76 & 740,00 & & \\
\hline & Total & 40 & & & & \\
\hline \multirow{3}{*}{$\begin{array}{c}\text { Hastalık } \\
\text { şiddeti }\end{array}$} & Nondominant & 10 & 14,80 & 148,00 & \multirow[t]{3}{*}{93,000} & \multirow[t]{3}{*}{0,026} \\
\hline & Bilateral & 34 & 24,76 & 842,00 & & \\
\hline & Total & 44 & & & & \\
\hline
\end{tabular}




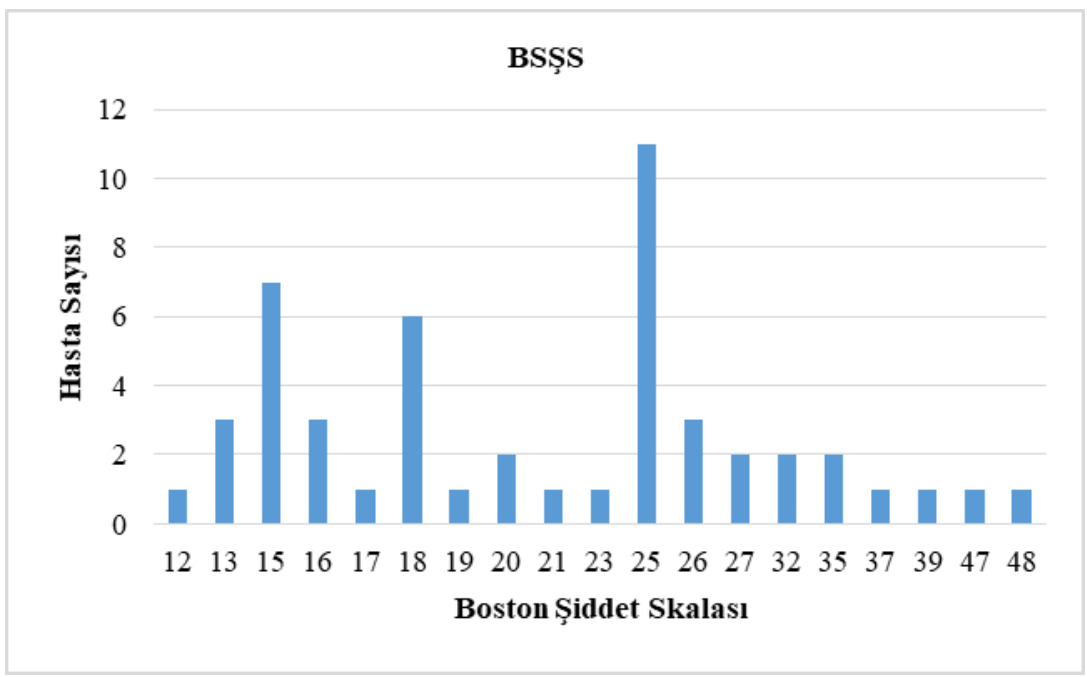

Şekil 1. Hasta sayısı ve Boston şiddet skalası değer leri dağılımı.

BSŞS: Boston semptom şiddet skalası. 


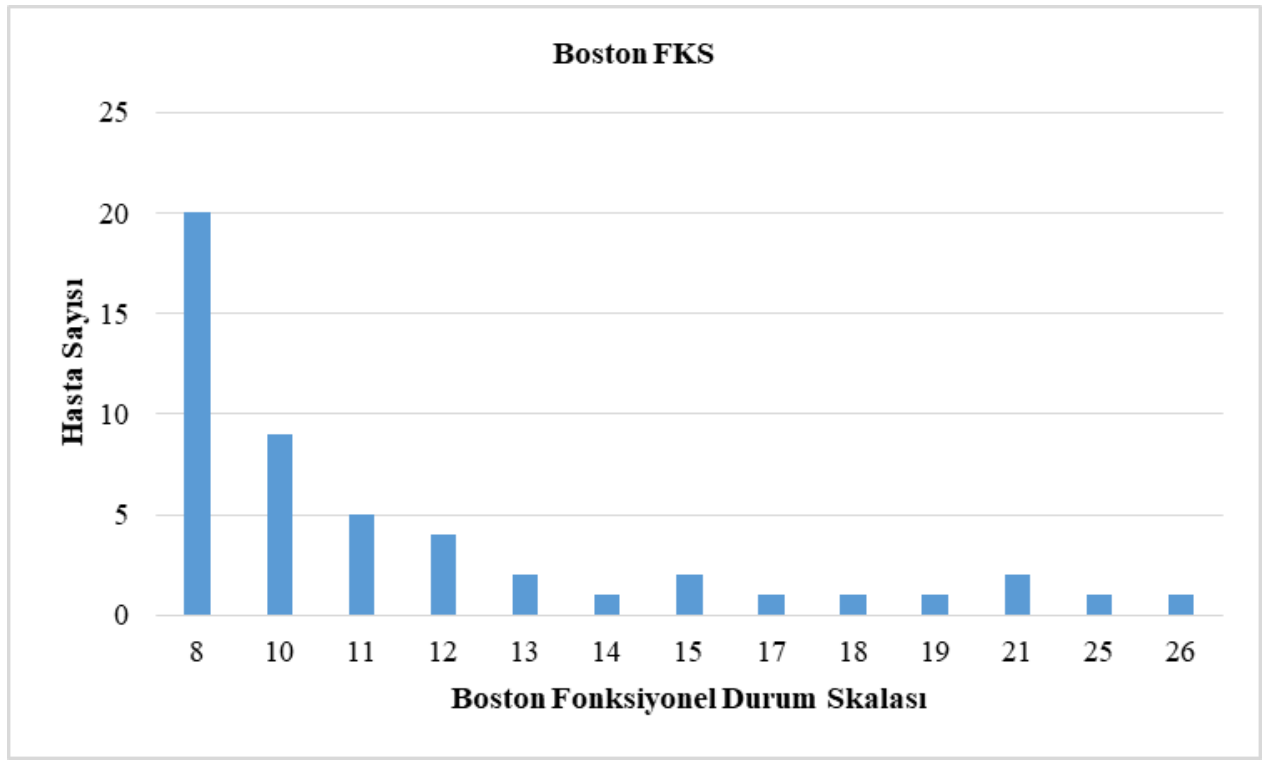

Şekil 2. Hasta sayısı ve fonksiyonel durum skalası değerleri dağılımı.

FKS: Fonksiyonel kapasite skoru. 